\title{
O subsetor de edificações da construção civil no Brasil: uma análise comparativa em relação à União Europeia e aos Estados Unidos
}

\author{
Luiz Carlos Brasil de Brito Mello UFF \\ Sérgio Roberto Leusin de Amorim UFF
}

\section{RESUMO}

O artigo tem como objetivo principal comparar o desempenho da construção europeia e da norte-americana, tomadas como benchmarking internacional, em relação à situação brasileira, de modo a identificar possíveis ações que contribuam para diminuir as diferenças de desempenho. Descreve-se, de modo sucinto, como a Construção Civil brasileira se insere no contexto econômico do país e são discutidos quais os principais problemas enfrentados e os desafios futuros. Ao mesmo tempo, pretende iniciar a discussão acerca das possíveis soluções para estes problemas.

É traçado, também, um breve panorama da Construção Civil na União Europeia, os desafios e problemas a serem enfrentados hoje e nos próximos anos. Apresentam-se, sucintamente, estudos que debatem tais problemas, apontando caminhos e possíveis soluções.

Em relação aos EUA, procura-se caracterizar a atual situação da construção civil, tendo como premissa a mesma apresentação feita para o Brasil e a União Europeia. Portanto, busca-se proporcionar um nivelamento da situação, importância, problemas e possíveis soluções para a Construção Civil dentre os três países. Assim, é possível tecer comparações entre os três, permitindo opções para as situações onde a Construção Civil brasileira esteja em desvantagem frente aos EUA e à UE.

\section{The subsector of buildings of the civil construction in Brazil: a $x$-ray of the sector compared to the European Union and the United States}

\begin{abstract}
The article has as its main objective to compare civil construction in Brazil relatively to the same industry in the United States and the European Union, that were used as benchmarking to Brazil, so it will be possible to find solutions that can contribute to minimize possible gaps that may exist. It is described as civil construction is very important to the Brazilian economy, although there are problems and challenges to be confronted. At the same time, the authors intend to open discussions about these problems. The authors do not intend to propose definitive solutions but to start the discussion about the problems and possible solutions.

It is described, briefly, what is the status of civil construction in the European Union, its main problems and solutions that are being used to solve them. This is done in order to see what of these solutions can be applied to Brazil.

The same is done relatively to the United States, having in mind that the same study structure used to Brazil and European Union was maintained, in order to help comparisons. So, the main objective is to establish a possibility to compare the situation of civil construction in Brazil, United States and European Union and verify what are the alternatives and solutions that are used there and that can be applied in Brazil.
\end{abstract}

\section{KEY WORDS}

Civil construction, buildings, modernization, benchmarking. 


\section{INTRODUÇÃO}

Na última década, o setor da Construção Civil vem passando por uma grande transformação, saindo de um longo marasmo, com poucos investimentos, para um período com grandes obras em andamento e fortes investimentos imobiliários. Nos últimos anos, esta mudança foi intensificada, graças à retomada de investimentos públicos, criação de diversas leis que facilitam a retomada de imóveis em caso de inadimplência, captação de recursos em bolsas e esforços do Programa Brasileiro de Qualidade e Produtividade - PBQP H, que disseminou os conceitos de gestão de qualidade. Isto se refletiu na adoção de novos modelos de organização e inovações tecnológicas em diversas empresas, criando um núcleo de empresas dinâmico e moderno dentro do setor, comparável a empresas europeias e norte-americanas do mesmo segmento. A presença de algumas empresas brasileiras no exterior é a prova mais evidente da capacidade técnica e financeira destes grupos empresariais modernos.

Entretanto, a maioria das empresas enfrenta dificuldades para atender a estas novas demandas e o quadro geral de desempenho, expresso pelas médias estatísticas é bastante aquém do desejável para responder adequadamente aos anseios da sociedade brasileira.

\section{OBJETIVO}

O presente artigo é resultado de uma pesquisa desenvolvida para o MDIC, Ministério do Desenvolvimento, Indústria e Comércio, em convênio com a FIESP - Federação das Indústrias do Estado de São Paulo com a finalidade de apresentar subsídios para uma política industrial para a construção civil-edificações. Os autores foram participantes do grupo responsável pelo desenvolvimento do trabalho e neste artigo pretendem abordar, especificamente, um dos temas lá estudados, a análise comparativa de desempenho e regulamentação da construção na União Europeia - UE nos Estados Unidos da América - EUA e o quadro brasileiro.

O objetivo principal é comparar o desempenho da construção europeia e da norte-americana, tomadas como benchmarking internacional, em relação à situação brasileira. É descrito, ainda, como a Construção Civil brasileira se insere no contexto econômico do país e são discutidos quais os principais problemas enfrentados e os desafios futuros. Ao mesmo tempo, pretende iniciar a discussão acerca das possíveis soluções para aqueles problemas.

É traçado, também, um breve panorama da Construção Civil na União Europeia, os desafios e problemas a serem enfrentados hoje e nos próximos anos. Apresentam-se, su- cintamente, estudos que debatem tais problemas, apontando caminhos e possíveis soluções. A avaliação de desempenho passa necessariamente pela avaliação de produtividade, volume e prazos de produção. Comparando-se estes dados com informações relativas ao contexto, tais como formação profissional, é possível termos um quadro relativo do setor analisado. Em que pesem certas discrepâncias de metodologia de apuração entre países, a comparação permite uma ordem de grandeza das variações. Esta metodologia, baseada em dados gerais de fontes oficiais infelizmente não permite comparações de segmentos particulares, como, por exemplo, o de edificações habitacionais. Mas no caso de diferenças gerais significativas o resultado é relevante e pode nortear ações a respeito.

Em relação aos EUA, procura-se caracterizar a atual situação da construção civil, tendo como premissa a mesma apresentação feita para o Brasil e a União Europeia. Portanto, busca-se proporcionar um nivelamento, visando atualizar a situação, importância, problemas e possíveis soluções para a Construção Civil. Assim, é possível tecer comparações entre os três, permitindo opções para as situações onde a Construção Civil brasileira esteja em desvantagem frente aos EUA e à União Europeia.

\section{METODOLOGIA}

$\mathrm{O}$ artigo teve como fonte o citado anteriormente, que se baseou em dados estatísticos públicos ou bibliografia consagrada. Inicialmente, buscou-se definir quais as possíveis palavras chaves do tema para que as consultas fossem facilitadas, selecionadas a partir dos temas de produtividade, produção da construção e formação profissional na área. Estas consultas foram executadas nas seguintes fontes: artigos, textos, obras, teses e dissertações, sites da Internet, órgãos estatísticos dos governos americano e da União Europeia, associações profissionais americanas e europeias, utilizandose fontes públicas e privadas.

Através de comparações entre os indicadores disponíveis, foram selecionados aqueles que guardavam condições de comparação, por terem conceitos similares. Deste modo, foi possível estabelecer uma análise do quadro de desempenho da construção americana, europeia e brasileira. No Quadro 1 são detalhados os indicadores escolhidos e a partir deste são estabelecidas algumas comparações.

Cabe destacar que uma das conclusões mais imediatas do estudo é a falta de dados sobre os setores da cadeia da construção civil brasileira. Existe uma grande dificuldade em obter informações confiáveis sobre todos os segmentos que dela participam, com algumas poucas exceções. A produção 
geral de edificações, seja em $\mathrm{m}^{2}$ ou em unidades construídas, um indicador relevante em todas as contas nacionais dos EUA e da UE, sequer está disponível. Além disto, as informações em raras ocasiões são plenamente comparáveis. Há também um grande descompasso entre as datas da referência e de publicação dos dados. Desta forma, algumas vezes é necessário um exercício analítico extenso para se chegar a uma conclusão, o que resulta em margens de tolerância acima do desejável. tos arquitetônicos, serviços de engenharia, empreiteiros etc. (AMORIM, 1995; MELLO, 2007).

A Construção Civil é integrada por uma série de atividades com diferentes graus de complexidade, ligadas entre si por uma vasta diversificação de produtos, com processos tecnológicos variados, vinculando-se a diferentes tipos de demanda. Ela abriga desde indústrias de tecnologia de ponta e capital intensivo, como cimento, siderurgia, química, até milhares de microempresas de serviços, a maior parte com baixo conteúdo tecnológico. Pode-se afirmar que uma das características marcantes do setor da Construção Civil é a sua heterogeneidade. $\mathrm{O}$ estudo da ABRAMAT (2007) tem a mais recente descrição desta ampla cadeia produtiva.

O macrossetor da Construção Civil é responsável por uma parcela importante do Produto Interno Bruto - PIB nacional, participando com $13,8 \%$ do

O trabalho de pesquisa e compilação de dados foi realizado no período março-junho 2008, mas as bases de dados brasileiras na ocasião só apresentavam resultados no máximo até 2005.

Em seguida, partindo-se de diversas fontes disponíveis, é feita uma análise sucinta da construção civil no Brasil, nos Estados Unidos e na União Europeia, bem como do quadro de desempenho da construção americana, europeia e brasileira em relação aos indicadores previamente escolhidos.

\section{COMPARAÇÃO COM ESTADOS UNIDOS E UNIÃO EUROPEIA}

Aqui é traçado um breve panorama da Construção Civil no Brasil, na União Europeia e nos Estados Unidos, os desafios e problemas a serem enfrentados hoje e nos próximos anos. O objetivo é a possibilidade de tecer comparações entre os três, permitindo opções para as situações em que a Construção Civil brasileira esteja em desvantagem frente aos EUA e à União Europeia.

\subsection{A Construção Civil no Brasil}

A Indústria da Construção Civil é composta por uma complexa cadeia produtiva que abrange setores industriais diversos, tais como: mineração, siderurgia do aço, metalurgia do alumínio e do cobre, vidro, cerâmica, madeira, plásticos, equipamentos elétricos e mecânicos, fios e cabos e diversos prestadores de serviços, como escritórios de proje-
PIB (FIESP, 2005). A tabela seguinte, adaptada de estudos da FIESP (2005), representa a participação em percentual do PIB nos subsetores do CONSTRUBUSINESS.

O setor da Construção Civil ocupa um papel importante no panorama econômico brasileiro, sendo responsável por gastos salariais de $\mathrm{R} \$ 15,5$ bilhões, correspondendo a um salário médio mensal de 2,7 salários mínimos, 5,2\% do PIB e, aproximadamente, $9 \%$ do pessoal ocupado (IBGE - Pesquisa Anual da Indústria da Construção, 2005). O PIB do setor, de acordo com o Valor Adicionado a Preços Básicos total do país divulgado pela FGV (2006), foi de R \$ 181,54 bilhões e o consumo intermediário da Construção Civil é de 181,69 bilhões de reais. Cerca de $55,6 \%$ do valor adicionado pela Construção Civil na economia está no setor informal (FGV, 2006), que paga carga tributária de $15,6 \%$, enquanto o setor formal contribui com 37\% do Valor Adicionado Bruto do setor, pagando carga

Tabela 1: A participação do CONSTRUBUSINESS no PIB.

\begin{tabular}{cc}
\hline Atividade & $\begin{array}{c}\text { Participação } \\
\text { no PIB }\end{array}$ \\
\hline Materiais de Construção & $4,6 \%$ \\
Outros Materiais & $0,8 \%$ \\
Máquinas e Equipamentos & $0,2 \%$ \\
Construção (Edificações, Construção Pesada) & $5,2 \%$ \\
Serviços (Projetos de Engenharia e Arquitetura, & $0,5 \%$ \\
Atividades Imobiliárias, Manutenção de Imóveis) & \\
\hline
\end{tabular}

Fonte: Adaptado da FIESP, 2005. 
tributária de 45,69\%. A Construção Civil paga 24,69\% do seu Valor Adicionado Bruto em tributos (CÂMARA BRASILEIRA DA CONSTRUÇÃO CIVIL, 2005).

Existem 105.469 empresas de Construção Civil no país, ocupando cerca de 1.600 .000 trabalhadores (IBGE - Pesquisa Anual da Indústria da Construção, 2005). Quase 93\% são micro e pequenas empresas que empregam até 29 trabalhadores. É importante ressaltar que, aproximadamente, 73\% destas empresas estão no segmento de edificações e obras de engenharia civil.

Atualmente, muitos empresários do setor de Edificações procuram capitalizar suas empresas, por meio do lançamento de ações em bolsa. De 2005 até novembro de 2007 foram feitos 28 lançamentos de construtoras na BOVESPA pela oferta pública de ações (também conhecida no mercado como Initial Public Offering - IPOs) com 9,5 bilhões de reais captados. Para que essas companhias pudessem oferecer suas ações na BOVESPA foram obrigadas a adotar medidas transparentes, auditar seus balanços e evitar a sonegação de impostos. A pioneira na abertura de capital foi a Cyrella.

Os financiamentos do setor imobiliário tiveram um crescimento de $430 \%$ no período $2000 / 2007$ e as empresas do setor estão capitalizadas, tendo em vista a captação de recursos, via oferta pública de ações. Além disto, como o crédito imobiliário em relação ao PIB ainda é muito pequeno, sendo cerca de $2 \%$, existe espaço para crescimento. Para fins de comparação, na Holanda tal crédito é de $105 \%$, na Espanha, $46 \%$ e em países com nível de desenvolvimento mais próximos ao do Brasil como Chile, Argentina e México são de, respectivamente, $17 \%, 4 \%$ e $11 \%$, demonstrando o espaço existente para crescimento.

Como resultado do sucesso destas captações, muitos empresários acreditam que o lançamento de ações no mercado é o caminho mais fácil para obtenção de recursos. Porém, esquecem que a preparação requer um caminho trabalhoso e de ajuste. Além do mais, a receptividade dos investidores para ações de companhias do setor da Construção Civil está diminuindo. Os especialistas acreditam que até o fim da década a consolidação das empresas deve ganhar força (Portal Exame, 2007; Portal Exame, 2008).

\subsection{Subsetores da Construção}

A Indústria da Construção Civil propriamente dita é classificada nos seguintes subsetores: (i) Subsetor de Materiais de Construção; (ii) Subsetor de Edificações; (iii) Subsetor de Construção Pesada. Existem, ainda, outras classificações tais como a que divide o setor em (SEBRAE-MG, 2005): a) Edificações; b) Construção Pesada; c) Montagem Industrial.

Trata-se, sem sombra de dúvida, de um segmento extremamente importante para o crescimento e desenvolvimento brasileiros, levando em conta as especificidades do setor, a saber (SEBRAE-MG, 2005): 1) elevado efeito multiplicador; 2) menor necessidade de investimento, devido à baixa relação capital / produto; 3) utilização intensiva de mão-de-obra, incluindo a não qualificada; 4) significativa porção dos investimentos e; 5) reduzido coeficiente de importação.

Um perfil setorial da Construção Civil brasileira, elaborado pelo SEBRAE-MG (2005), apresenta as seguintes características para o setor:

a) demanda apresentando forte correlação com a evolução da renda interna e condições de crédito;

b) intensividade na geração de emprego, principalmente mão-de-obra desqualificada;

c) pequena participação do emprego formal na parcela total de empregados ocupados no setor;

d) existência de diversos problemas quanto ao cumprimento de normas técnicas e padronização;

e) níveis de competitividade e produtividade abaixo do padrão existente nos países desenvolvidos; e

f) pouca atualização nos aspectos tecnológicos e de gestão, quando comparados aos padrões dos países desenvolvidos.

\subsection{0 subsetor de Edificações}

O subsetor de edificações, foco do presente estudo, participa com 2,05\% do PIB nacional e 39,7\% do PIB da construção (PAIC, 2005). Este foco ocorrerá devido às peculiaridades e restrições ao desenvolvimento deste segmento no setor, tais como (MELLO, 2007):

a) baixa eficiência produtiva;

b) qualidade e produtividade insatisfatórias;

c) pouco afeito a modificações;

d) utilização de mão-de-obra de baixa qualificação e;

e) alta rotatividade de pessoal.

\subsection{A Construção Civil na União Europeia}

A indústria da Construção Civil é importante para a economia europeia, responsabilizando-se por cerca de 4 a $9 \%$ do PIB dos países componentes da União Europeia respondendo por cerca de 4 a 10\% do índice de desemprego (European Foundation for the Improvement of Living and Working Conditions, 2005). A Construção Civil europeia, relativamente à Comunidade Europeia, tem como principais características (European Monitoring Center on Change, 2005): a) setor interno fortemente privilegiado; b) grande número de micro e pequenas empresas, incluindo profissionais autônomos; c) número razoável de grandes empresas de porte internacional, que, entretanto, vem decrescendo quando é feita uma comparação com o resto do mundo; d) baixo nível de investimento em Pesquisa e Desenvolvimento, especialmente quando comparada com o Japão. 
Atualmente, a indústria da Construção Civil na Europa, tem alguns importantes desafios a serem vencidos. Vários fatores externos estão modificando o ambiente competitivo da indústria, e as empresas, empregados e associações do segmento terão que fazer frente a estes desafios. Tais desafios provêm do aumento da UE pelo acréscimo de novos países, pela nova regulamentação proposta para serviços no mercado interno e pelo aumento da globalização do mercado, entre outros fatores. A competição, no entanto, varia de um subsetor da indústria da construção para outro e de um país da União Europeia para outro. Outro desafio relevante é o envelhecimento da população europeia, trazendo dificuldades para o recrutamento de mão-de-obra para a Construção Civil. No entanto, o ingresso de novos países na União Europeia traz novas demandas e novos mercados para serem desenvolvidos.

construção com a identificação prévia de falta de materiais, mão-de-obra e equipamentos estão entre os elementos para atingir os objetivos pretendidos. Entretanto, para utilizar estes novos conceitos, é necessário que a indústria da construção na UE contrate pessoal com novas qualificações (European Foundation for the Improvement of Living and Working Conditions, 2005). Esta busca pelas novas qualificações é uma necessidade do setor para crescer, fazer frente à competição global crescente e responder aos anseios dos clientes por maior produtividade e qualidade. É, também, uma necessidade particular das empresas para que possam continuar competitivas e, em última análise, dos empregados do setor para que possam manter sua empregabilidade. Segundo o European Monitoring Center on Change (2005) esta necessidade não é um problema para as grandes empresas do setor que estão equipadas para suprir estas necessidades. Porém, para as pequenas e médias empresas do setor, que são em maior número, este problema é grave, já que não possuem as habilidades necessárias para fazer frente ao desafio.

A indústria da construção na UE divide-se em cinco sub-setores (EUROPEAN MONITORING CENTRE ON

A recente conscientização de sustentabilidade leva a novas exigências por parte dos clientes, públicos e privados, determinando a criação de novos requerimentos e regulamentações, tanto em âmbito nacional como na União Europeia. As autoridades reguladoras da União Europeia estão atentas e respondem a estas demandas. Um outro fator de pressão no setor diz respeito aos novos padrões de saúde e segurança nos processos construtivos, obrigando a mudança e aprimoramento dos referidos processos. A construção, por intermédio de Parcerias Públicas Privadas - PPP, é um novo mercado a ser explorado pelas empresas do setor. Estas parcerias trazem novos tipos de necessidades para o financiamento e operação dos empreendimentos.

Outra inovação na Construção Civil europeia é a utilização da Tecnologia da Informação em materiais e edificações (prédios inteligentes), em comunicações com clientes e associados nos empreendimentos, no controle das atividades, materiais e equipamentos, no suprimento de materiais e equipamentos com o $e$-business, na utilização de equipamentos de inteligência virtual e no projeto e construção.

Com a utilização de técnicas, como a "lean construction", a indústria da Construção Civil pretende minimizar erros, reduzir custos e prazos e melhorar a qualidade. O emprego de elementos pré-fabricados, planejamento das etapas de
CHANGE, 2005): a) Preparação de terrenos consistindo em demolições, terraplenagem, furação e cravação de estacas, fundações; b) Edificação de construções completas, consistindo em obras de engenharia civil, construção de edificações, construção de estradas, autoestradas, aeroportos e instalações esportivas e outras construções envolvendo necessidades especiais; c) Instalações elétricas, tubulações, isolamento e outras instalações; d) Acabamento; e) Aluguel de equipamento com operador para construção ou demolição.

O setor de edificação de construções completas é o sub-setor mais importante, sendo responsável por mais da metade do emprego e do valor adicionado. A maior parte do emprego restante está no subsetor de instalações elétricas, tubulações, isolamento e outras instalações, bem como no subsetor de acabamento (EUROPEAN MONITORING CENTRE ON CHANGE, 2005).

\subsection{A Construção Civil nos Estados Unidos}

A indústria da Construção Civil americana representa 8,47\% do PIB americano, em 2007 (CONSTRUCTION INDUSTRY ROUNDTABLE, 2007). A indústria da Construção Civil nos Estados Unidos, sob muitos aspectos, assemelha-se à da União Europeia. Suas atividades incluem 
a construção de novas edificações e estruturas, preparação de terrenos (site preparation), adições e modificações em edificações e estruturas existentes, manutenção e reparos de estruturas e edificações existentes. A construção se divide em três segmentos: 1) construção de edificações, que inclui os chamados "general contractors", responsáveis pelas edificações residenciais, comerciais e outros tipos de edificações; 2) construção pesada incluindo estradas, rodovias interestaduais, pontes, túneis e outros projetos especiais; 3) serviços especiais englobando atividades como pintura, hidráulica, eletricidade etc.

A indústria da Construção Civil é uma das maiores atividades econômicas nos Estados Unidos, abrangendo cerca de 883.000 empresas. Deste total, aproximadamente 268.000 estão envolvidas na construção de edificações, 64.000 empresas atuam na construção pesada e 550.000 empresas cuidam dos serviços especiais. A maior parte destas empresas é de pequeno porte, sendo que cerca de $65 \%$ das empresas empregam até quatro empregados e apenas $1 \%$ emprega 100 ou mais empregados (US BUREAU OF LABOR STATISTICS, 2006). A indústria da Construção Civil, segundo o Bureau of Labor Statistics, empregava, em 2006, quase 7,7 milhões de pessoas (fixas e terceirizadas) e 1,9 milhão de autônomos. Aproximadamente $64 \%$ dos empregos na Construção Civil estavam no âmbito das empresas de serviços especiais, $24 \%$ na construção de edificações e o restante estava empregado nas empresas de construção pesada. Atuam diretamente para os proprietários das edificações residenciais e comerciais 1,9 milhão de autônomos, trabalhando em adições e remodelações, ou agem como "contractors" para estas atividades.

Os "contractors" para serviços especiais geralmente trabalham em uma só especialidade, como pintura, carpintaria ou instalação elétrica, ou duas ou mais atividades análogas como tubulação e aquecimento. Geralmente, trabalham sob as ordens do "general contractor" ou de engenheiros arquitetos ("architect").

A Construção Civil americana é responsável por $22 \%$ da produção total mundial do setor.

O déficit de pessoal qualificado na Construção Civil americana tem levado a um crescimento da mecanização como forma de incrementar a produtividade e suprir a deficiência. Outra providência é o aumento da utilização de conjuntos pré-fabricados (CONSTRUCTION INDUSTRY INSTITU$T E, 2003)$. Todavia, deve ser ressaltado que estas medidas não representam uma alternativa real para a substituição de pessoal qualificado. Empresas com novas tecnologias também requerem pessoal qualificado.
Em seguida, será traçado um quadro comparativo entre alguns indicadores, previamente discutido com os outros pesquisadores envolvidos no trabalho origem do presente artigo e já mencionado, que permita uma comparação entre a Construção Civil brasileira frente à europeia e à americana.

\subsection{Levantamento e análise do quadro de desempenho e regulamentação da construção na Europa e nos Estados Unidos}

A Construção Civil, como observado no Quadro 1, ocupa papel importante nas economias brasileira, americana e europeia. Apesar da imensa diferença entre o tamanho dos respectivos PIBs, existem similaridades entre as três áreas em relação à Construção Civil. Algumas podem ser citadas: a) O setor é constituído por pequenas e médias empresas; b) Todas as empresas apresentam problemas em relação à qualificação da mão-de-obra; c) Apresentam problemas em relação à segurança do trabalho; e d) São as maiores empregadoras em suas economias.

Existe uma diferença significativa em relação ao faturamento das empresas, em cada região, de acordo com cada economia. O faturamento das empresas brasileiras é aproximadamente $8,6 \%$ do faturamento das empresas americanas, o que é explicável pela diferença entre o tamanho das economias americana e brasileira. A Construção Civil americana apresenta, atualmente, sérios problemas, devido à crise imobiliária causada pelos empréstimos podres.

Fica constatada uma enorme diferença ao se comparar a produtividade obtida pelos empregados no setor. A produtividade europeia é $75 \%$ da americana e a brasileira é $15 \%$ da americana, demonstrando que há um imenso "gap" a ser diminuído entre as duas, conforme Gráfico 1.

O prazo médio para obras de edificação no Brasil é três vezes maior do que nas construções americanas e duas vezes o despendido nas construções europeias. O licenciamento de obras no Brasil leva duas vezes mais tempo do que nos Estados Unidos e é, em média, 50\% maior do que aquele gasto na União Europeia. O gráfico seguinte ilustra estas diferenças em relação às dimensões: prazo médio de licenciamento 
Quadro 1: Comparativo de indicadores entre Brasil, EUA e UE.

\begin{tabular}{|c|c|c|c|}
\hline Indicadores & Brasil & EUA & UE \\
\hline$\%$ PIB & $5,2 \%(1)$ & $8,47 \%(11)$ & $10,2 \%(21)$ \\
\hline Faturamento & US\$ 40,98 bilhões (2) & US\$ 475,6 bilhões (12) & US\$ 710 bilhões (22) \\
\hline Número de empresas & $105.459(1)$ & $818.000(13)$ & $807.100(23)$ \\
\hline Faturamento médio & US\$ 388.590* & US\$ 581.420* & US\$ 879.690* \\
\hline Pessoal empregado & $1.550 .000(1)$ & $7.689 .000(14)$ & 4.519 .000 \\
\hline Pessoal ocupado & $5.170 .000(3)$ & 9.589 .000 & 4.519 .000 \\
\hline Produtividade média & US\$ 6.177,76 / trabalhador (4) & US\$ 41.528,00 /trab. (15) & US\$ 31.247,44/trab (24) \\
\hline Rentabilidade & $24,35 \%(5)$ & $67,5 \%(16)$ & não foram obtidos dados \\
\hline Número de eng ${ }^{o s}$ e gerentes & $125.420(6)$ & $623.000(17)$ & $550.530(25)$ \\
\hline Engenheiros/ MO total & $2,4 \%$ & $6,5 \%$ & $12,2 \%$ \\
\hline Engenheiros/ MO empregada & $8 \%$ & $8 \%$ & $12,2 \%$ \\
\hline $\begin{array}{l}\text { Tempo de formação de pessoal } \\
\text { nível superior }\end{array}$ & 5 anos (7) & 5 anos (18) & $5-7$ anos (26) \\
\hline $\begin{array}{l}\text { Tempo de formação de pessoal } \\
\text { nível médio }\end{array}$ & $2-3$ anos (8) & 3 anos (18) & $2-3$ anos (26) \\
\hline $\begin{array}{c}\text { No de normas técnicas para } \\
\text { Construção Civil }\end{array}$ & $938(9)$ & ND & $1.733(27)$ \\
\hline Prazo médio de obras de edificação & 30 meses (10) & 10 meses (19) & 14,3 meses (28) \\
\hline Prazo médio de licenciamento & 66 dias $(10)$ & 30 dias (20) & 44 dias (29) \\
\hline
\end{tabular}

(1) PAIC (2005) e considerado valor do PIB 2005 = R\$ 1.937 trilhão (IBGE).

(2) PAIC (2005). US\$ $1,00=R \$ 2,433$.

(3) Para emprego formal, utilizado PAIC 2005-IBGE e para informal estimado utilizando a relação de 2003 para emprego formal e informal (SINDUSCON-SP, 2003).

(4) FGV (2006). US\$ $1,00=R \$ 2,3504$.

(5) PAIC (2005). Considerada receita bruta de $\mathrm{R} \$ 100$ bilhões e $\mathrm{R} \$ 75,65$ bilhões de gastos totais (gastos com pessoal + consumo de materiais + outros custos e despesas). A Rentabilidade é entendida como: (Receita Bruta - Gastos Totais)/ Receita Bruta.

(6) CREA (2008). Quantitativo de profissionais.

(7) MEC (2008). Diretrizes curriculares dos cursos de graduação em Engenharia Civil.

(8) MEC (1999). Diretrizes Curriculares Nacionais para a Educação Profissional de Nível Técnico.

(9) ABNT (2008).

(10) SINDUSCON DF (www.sinduscondf.org.br) . (Acesso em 22/3/2008).

(11) Construction Industry Institute (2007).

(12) US Census Bureau.

(13) Consideradas, apenas, as empresas de atuação na área de construção de imóveis (US Bureau of Labour Statistics).

(14) U.S. Department of Labour-Bureau of Labor Statistics, 2006.

(15) US BLS (2006)

(16) US Census Bureau (2002). Considerada receita bruta de US\$ 475,6 bilhões e US\$154,49 bilhões de gastos totais (gastos com pessoal $=$ US\$ 53,48 bilhões + consumo de materiais $=$ US\$ 97,69 bilhões + outros custos e despesas = US\$ 3,321 bilhões). A Rentabilidade é entendida como: (Receita Bruta Gastos Totais) / Receita Bruta.

(17) U.S. Department of Labour - Bureau of Labour Statistics (2008).

(18) NCARB (2008). National Council of Architectural Registration Boards.

(19) Dados retirados de http://nwjoinery.com. Acesso em 23/3/2008.

(20) Dado válido para a cidade de Houston. Ver: www.publicworks.houstontx.gov. Acesso em 25/3/2008.

(21) ECTP (2007).

(22) http://www.businessstrategies.co.uk . Acesso em 23/3/2008.

(23) European foundation for the improvement of living and working conditions (2005).

(24) Valor adicionado de 134,6 bilhões de Euros para a construção imobiliária (European foundation for the improvement of living and working conditions, 2005) e 4.519.000 empregados na Construção Civil imobiliária (Eurostat, 2008. http://epp.eurostat.ec.europa.eu. Acesso em 26/3/2008). 1 Euro = US\$ 0,953023

(25) Eurostat (2008)

(26) MEC/Espana (2007). Implantación del nuevo sistema educativo

(27) CEN (2008).

(28) Estimado, considerando-se a produtividade americana como base 100 e a europeia como base 70.

(29) http://www.oracle.com Acesso em 27/3/2008.

* Dado obtido pela divisão do Faturamento pelo número de empresas. 
e prazo médio de construção no Brasil, Estados Unidos e União Europeia.

Além do fato de que a produtividade obtida na construção civil no Brasil apresenta diferenças significativas em relação à dos Estados Unidos e da União Europeia, mesmo internamente, pode ser observado que a construção civil possui uma produtividade que fica aquém daquela obtida em outros setores industriais. Isto demonstra o menor desempenho do setor não só externamente como, também, em relação a outros segmentos produtivos. Isto fica claramente demonstrado no Gráfico 3, onde é apresentada uma comparação entre a produtividade de algumas indústrias selecionadas aleatoriamente, a saber: extração de petróleo, siderurgia, caldeiraria, máquinas e equipamentos, automóveis, construção predial (formal+informal), construção predial formal. Os valores foram obtidos pela divisão do valor agregado pelo número de funcionários (IBGE, 2005). Observa-se que os valores obtidos pela Construção Civil são significativamente menores que os das demais indústrias. Esta diferença pode ser explicada por fatores tais como (AMORIM, 1995; MELLO, 2007): a) Trabalhadores com baixa qualificação; b) Pouco interesse das pequenas e médias empresas em melhorar o nível de qualificação dos empregados; c) Baixo investimento das empresas em pesquisa e desenvolvimento; d) Ausência

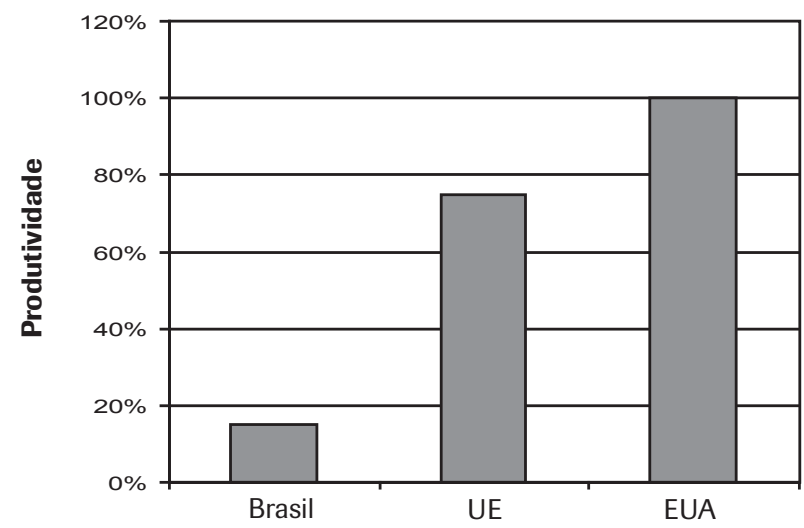

Sequência 1

Gráfico 1: Comparação entre a produtividade brasileira, americana e europeia na Construção Civil.

Fonte: Autores, com base nos dados de FGV, 2006; US Census Bureau, 2002 e European Foundation for the Improvement of working and Living Conditions, 2005. de investimentos e conhecimento das empresas em técnicas de pré-fabricação, modularização, gerenciamento e implantação de sistemas e ferramentas de TI; e) Pouca utilização de sistemas de planejamento do trabalho; f) Altas taxas de desperdício de materiais e retrabalho.

\section{E ste estudo insere-se nos esforços da academia em Ediscutir a construção civil e buscar possíveis caminhos para o setor que permitam seu pleno desenvolvimento.}

Esta baixa produtividade é influenciada por outros fatores, tais como o fraco desempenho tecnológico da cadeia da construção, que é evidenciado pelo volume de patentes registradas. Isto é demonstrado pelo Gráfico 4 que mostra a comparação entre os setores classificados pelo INPI. Fica evidente que a Construção Civil vem perdendo terreno, mesmo que o Gráfico 5 mostre que o volume de pedidos de patentes tenha acompanhado de maneira próxima a evolução do PIB setorial. Embora internamente na construção civil haja grandes alterações, comparativamente a outros setores, a construção apresenta menor dinamismo tecnológico.

Na cadeia de produção na Construção Civil, as construtoras formais são responsáveis por $26,6 \%$ do valor adicionado em todo o setor, seguidas pelas empresas formais com

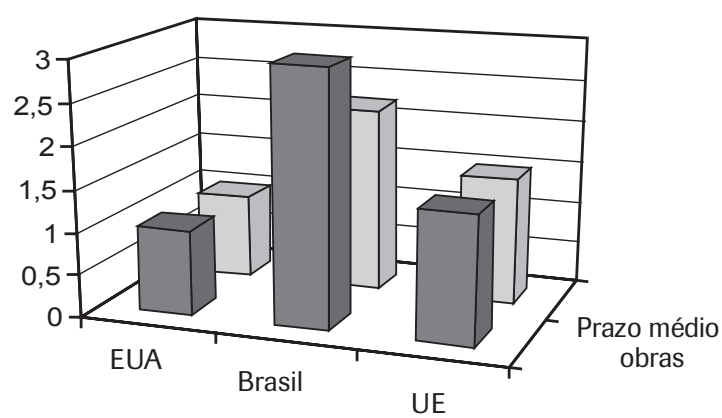

Prazo médio obras

Prazo médio licenciamento

Gráfico 2: Comparações entre prazos de licenciamento e construção no Brasil, EUA e UE.

Fonte: Autor, com base nos dados de Sinduscon DF; www.nwjoinery.com; www.publicworks.houstontx.gov; www.oracle.com.

Acesso em março 2008. 
$21,0 \%$ e, logo adiante, pelas obras informais, como mostra o Gráfico 6

Neste gráfico, percebe-se que as empresas formais no setor produtivo da Construção Civil (21\%) agregam três vezes mais valor que as informais $(6,1 \%)$, sendo superadas, somente, pelas construtoras $(26,6 \%)$. A informalidade na cadeia produtiva de materiais de construção é estimulada pela falta de fiscalização no trabalho pelos órgãos de saúde e segurança, pela escassez de normas técnicas para a produção e pelo ainda incipiente processo de certificação de produtos. A parcela informal da indústria de materiais de construção não apresenta produtividade representativa no contexto do setor, sendo aproximadamente um terço da produção da indústria formal, que é de $16 \%$. Também a ocupação da indústria informal é responsável por menos da metade do pessoal ocupado no setor formal. Esses números dão indicação imediata da menor produtividade do setor informal.

Pesquisas desenvolvidas entre 1998 e 2002 verificaram a necessidade de adequação do setor às exigências de mercado. Assim, na última década, houve um grande esforço para a implantação de programas setoriais de qualidade, como parte do $\mathrm{PBQP}-\mathrm{H}$, apresentando avanços significativos na qualidade de materiais e componentes da Construção Civil. Atualmente, existem 25 Programas Setoriais de Qualidade PSQs, e em alguns segmentos já foi superado o percentual de 90\% de conformidade para materiais que compõem a Cesta Básica da construção (PBQP-H, 2006).

Outras medidas de modernização e adequação da indústria da Construção Civil às novas realidades brasileiras são: o Sistema Nacional de Avaliações Técnicas - SINAT, que tem por objetivo suprir as lacunas de normalização técnica, quando esta não for prescritiva, e os processos de certificação.

A busca pela certificação de produtos, por parte das empresas da Construção Civil, visa principalmente atender o mercado internacional, pois a certificação confere status tanto no meio empresarial quanto no mercado consumidor. Esta situação favorece não só o consumidor final, mas toda a cadeia produtiva. Neste cenário, percebe-se que a questão ambiental não constitui fator principal para serem feitas adequações às recomendações de conformidade, mas à lógica financeira. Apesar disto, muitas empresas já conseguem auferir lucro promovendo cuidados com o meio ambiente, ao adotarem, por exemplo: fonte energética menos poluidora; Mecanismo

Produtividade(R\$/trab.)

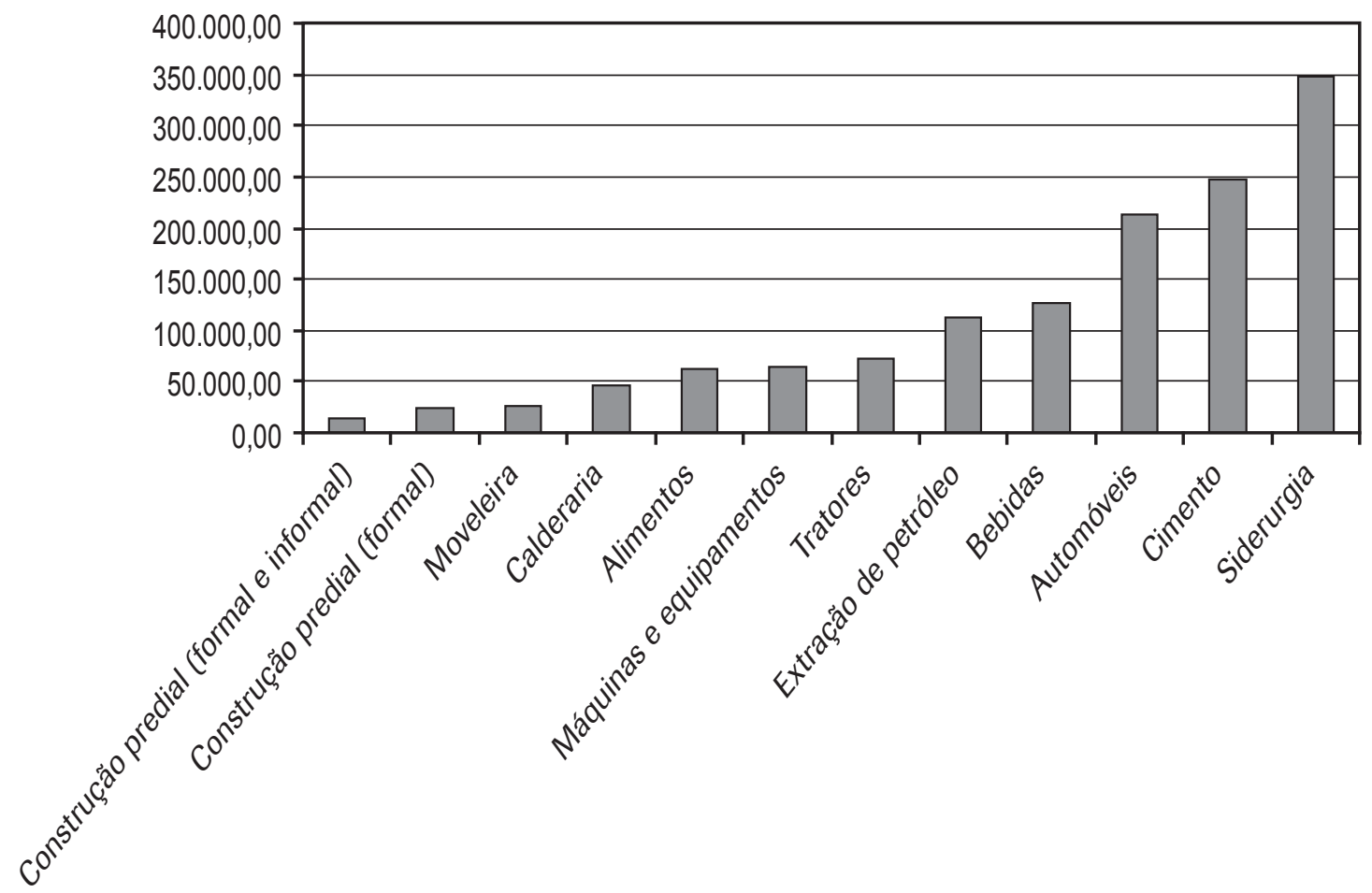

Gráfico 3: Comparações entre produtividade de indústrias brasileiras.

Fonte: Autores, com base nos dados do IBGE, 2005 
de Desenvolvimento Limpo - MDL; implantação da cogeração de energia em seus processos produtivos; substituição de matérias-primas não renováveis por produtos reciclados.

\section{ANÁLISE E PROPOSTAS}

\subsection{Caracterização dos pontos críticos}

Levantamentos junto às entidades representativas, (AMORIM, 2008) indicaram um quadro dos gargalos na Construção e possíveis ações para suplantá-los.

O sintoma central da construção pode ser caracterizado pela sua baixa produtividade, cujas principais causas podem ser enumeradas como sendo:
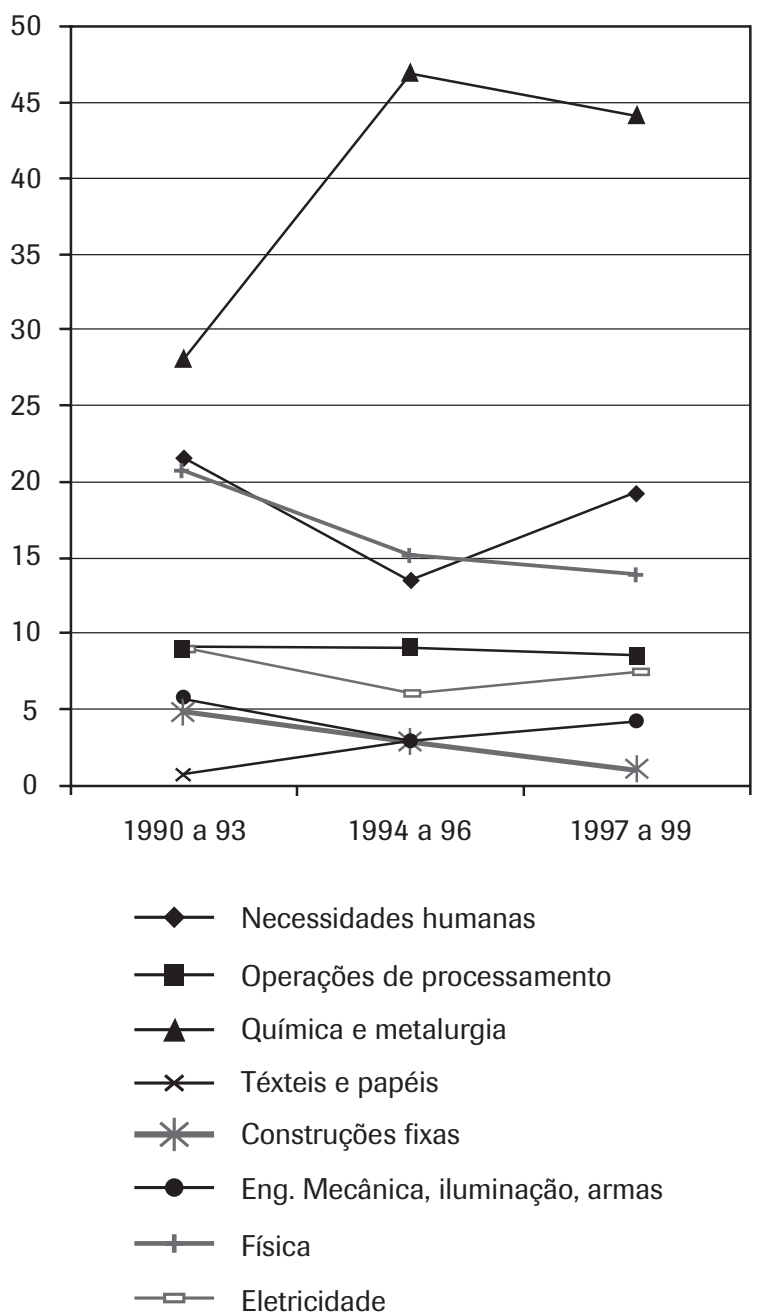

Gráfico 4: Patentes por setores. Fonte: INPI, 2008. Acesso em 23 mar. 2008. a) Baixa qualificação e desatualização da mão-de-obra;

b) Falta de padronização e não conformidade dos materiais;

c) Quadro regulatório burocrático e deficiente;

d) Pouca utilização da Tecnologia da Informação;

e) Pouca utilização de equipamentos que permitam alta produtividade; $\mathrm{e}$

f) Alta incidência de tributos e encargos.

Note-se que diversos aspectos, que contribuem para a baixa produtividade, estão inter-relacionados ou têm a mesma origem. Por exemplo, a falta de padronização e de modularidade de componentes deriva de aspectos contidos no setor, tais como desconhecimento das normas ou devido a estratégias comerciais de diferenciação, mas vincula-se, também, aos Códigos de Obras que impõem padrões mínimos não-conformes com a coordenação modular. É, também, resultado da formação de profissionais de projeto de que não trata este tema, nem valoriza a economia no projeto e nos produtos do projeto.

Por outro lado, o uso restrito de componentes e equipamentos de alta produtividade explica-se, em boa parte, pela questão da tributação e alta informalidade na produção da obra, em alguns subsetores do macrocomplexo da construção. Mas vincula-se, também, a alguns modelos de produção, em que o prazo de execução deve ser mais estendido para atender o fluxo de caixa dos proprietários. Por exemplo, obras realizadas em regime de condomínio, em que os adquirentes contribuem, mensalmente, com parcelas restritas, tendem a dispor de prazos incompatíveis com os custos de aluguel de equipamentos por longos períodos.

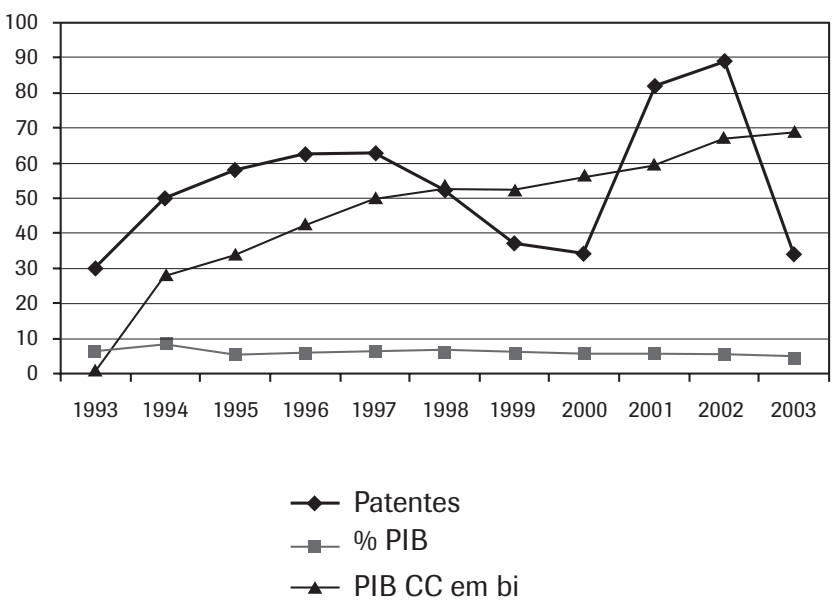

Gráfico 5: Evolução Patente e participação da construção no PIB.

Fonte: Elaborado pelo autor a partir de INPI, 2008; SENAI, 2005 e IBGE, 2005. 


\section{CONSIDERAÇÕES FINAIS}

A construção civil no Brasil, como detalhado no presente artigo, ocupa um papel importante no panorama econômico, tendo participação direta no Produto Interno e agindo sobre uma extensa cadeia produtiva de fornecedores, serviços de comercialização e manutenção (MELLO, 2007). Para manter esta importância, a construção civil vem passando por grandes mudanças, que foram facilitadas por fatores tais como a retomada dos investimentos públicos, a criação de diversas leis que

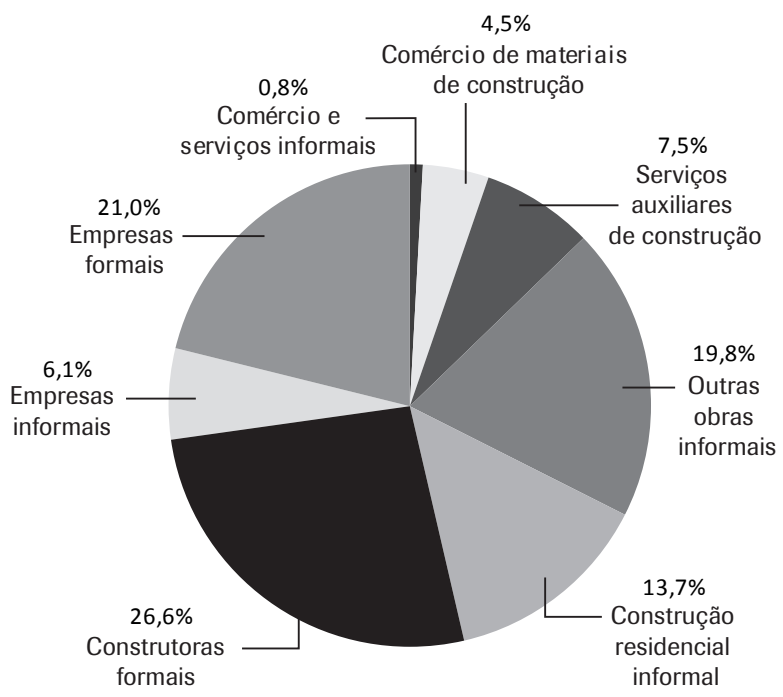

\section{Gráfico 6: Distribuição de VA na cadeia da Construção Civil.}

Fonte: FGV-Projetos, 2004. facilitam a retomada de imóveis em caso de inadimplência, a captação de recursos em bolsas e os esforços do Programa Brasileiro de Qualidade e Produtividade - PBQP H, que difundiu os conceitos de gestão de qualidade. Hoje, o setor passa por problemas de falta de mão-de-obra especializada que possa fazer frente às necessidades de crescimento do setor. No entanto, ainda persistem problemas de qualidade e produtividade que impedem o pleno desenvolvimento setorial. Os aspectos de não conformidade, baixa qualidade e informalidade da mão-deobra não foram, ainda, devidamente enfrentados e resolvidos.

Neste artigo, buscou-se fazer uma comparação entre a construção civil brasileira em relação à europeia e à americana, focando principalmente o subsetor edificações. Para que estas comparações fossem facilitadas, foram utilizados indicadores, previamente acordados entre os autores e que estivessem respaldados pela bibliografia. Este estudo se insere nos esforços da academia em discutir a indústria da construção civil e buscar possíveis caminhos para o setor, que permitam seu pleno desenvolvimento e a eliminação dos hiatos entre a construção civil brasileira frente aos países mais desenvolvidos. O déficit habitacional brasileiro hoje se aproxima dos oito milhões de unidades, crescendo em decorrência de que a produção atual não atende sequer à demanda do crescimento da população (PLANHAB, 2008), tampouco às novas demandas decorrentes da melhoria de renda. A mudança do patamar de produção para o volume necessário a estas demandas exige um novo paradigma organizacional para o setor. A comparação com países que apresentam bons indicadores de produtividade pode colaborar para que esta barreira seja ultrapassada.

Não é pretensão dos autores esgotar o assunto nem apresentar soluções definitivas, mas sim estimular a discussão alternativa para a discussão e o aprimoramento.

\section{Artigo recebido em 13/11/2007 Aprovado para publicação em 07/05/2009}

\section{REFERÊNCIAS}

AMORIM, S. R. L. Tecnologia, Organização e Produtividade na Construção. 1995. Tese (Doutorado em Engenharia de Produção), Programa de Pós Graduação em Engenharia de Produção, Universidade Federal do Rio de Janeiro. Rio de Janeiro 1995.

AMORIM et al. Proposta de Política Industrial para construção civil, Edificações. DECONCIC, FIESP, São Paulo, 2008.
BRASIL. MEC/MTE. Sistema Nacional de Certificação Profissional: Proposta Governamental. Brasília, 2005.

BRASIL. Ministério da Educação - MEC. Conselho Nacional de Educação - CNE. Parecer CNE/CES 1.362/2001. Diretrizes Curriculares Nacionais dos Cursos de Engenharia. Brasília, 2002.
CAMARA BRASILEIRA DA INDÚSTRIA DA CONSTRUÇÃO. Fundação Getúlio Vargas. A Construção em Números. Belo Horizonte. Disponível em www.cbicdados.com.br. Acesso em $5 / 3 / 2008$

CONSELHO FEDERAL de ENGENHARIA, ARQUITETURA Y AGRONOMIA - CONFEA Anexo I da Resolução $n^{0} .1010$ de 22 de agosto de 2005. Sistematização das atividades profis- 
sionais - Preâmbulo. Disponível em: www. confea.org.br. Acesso em 4 mar. 2008.

CONSTRUCTION INDUSTRY ROUNDTABLE. 2007. Disponível em ww.cirt.org. Acesso em 4 mar. 2007.

EUROPEAN FOUNDATION FOR THE IMPROVEMENT OF LIVING AND WORKING CONDITIONS. 2005. Disponível em: www.eurofound.europa.eu. Acesso em 25/2/2008.

EUROPEAN MONITORING CENTRE ON CHANGE. EMCC dossier on the European construction sector. Disponível em: ww.eurofound. eu.int. Acesso em 18 fev. 2008.

FGV PROJETOS. A tributação na indústria brasileira de materiais de construção. São Paulo: ABRAMAT, 2006a.

FGV PROJETOS. A carga tributária incidente no preço de habitações populares. São Paulo: SINDUSCON-SP, mimeo, 2006b.

FUNDAÇÃO GETÚLIO VARGAS-PROJETOS. Informalidade e Carga Tributária. Propostas para superação dos obstáculos na Construção Civil. SINDUSCON-SP/FGV - Projetos, 2004. disponível em: http://www.sindusconsp. com.br/especiais/forum_competitividade/
Informalidade_e_Carga_tributaria_FGV_ Projetos.pdf. Acesso em 1ํo jun. 2008.

INSTITUTO BRASILEIRO DE GEOGRAFIA E ESTATÍSTICA - IBGE. Contas Nacionais. Diretoria de Pesquisas. Disponível em: http:// www.ibge.gov.br. Acesso em 01 mar. 2008.

INSTITUTO BRASILEIRO DE GEOGRAFIA E ESTATÍSTICA - IBGE. Tabelas sinóticas. Sistema de Contas Nacionais - Brasil 2004-2005. Brasília, 2007. Disponível em: ttp://www.ibge.gov.br/ home/estatistica/economia/contasnacionais/ referencia2000/2004_2005/tabsinotica14.pdf. Acesso em: 10 mar. 2008.

MELLO, L. C. B. B. Modernização das pequenas e médias empresas de Construção Civil: impactos dos programas de melhoria da gestão da qualidade. 2007. Tese (Doutorado em Engenharia Civil) - Programa de Pós Graduação em Engenharia de Civil, Universidade Federal Fluminense. Niterói-RJ, 2007.

NCARB, National Council of Architectural Registration Boards. Disponível em: http://www. ncarb.org/. Acesso em 12 abr. 2008.

PROGRAMA BRASILEIRO DA QUALIDADE E PRODUTIVIDADE - HABITAÇÃO (PBQP-H) - Ministério das Cidades. Disponível em: http://www.cidades.gov.br. Acesso em 10 abr. 2006.

SERVIÇO BRASILEIRO DE APOIO À MICRO E PEQUENA EMPRESA - MINAS GERAIS SEBRAE-MG. Minas Gerais. Perfil Setorial da Construção Civil, 2005. Disponível em http:// www.sebrae-mg.com.br. Acesso em 31 ago. 2005.

SINDICATO DE INDÚSTRIA DA CONSTRUÇÃO CIVIL NO ESTADO DO RIO DE JANEIRO SINDUSCON-RIO. Estatísticas do CAGED - Construção Civil - Maio de 2006. Rio de Janeiro, 2006. Disponível em: http://www. sinduscon-rio.com.br/doc/cag.pdf. Acesso em 9 mar. 2008.

Os incentives das prefeituras paulistas. Disponível em www.sindusconsp.com.br. Acesso em mar. 2008.

SINDICATO DE INDÚSTRIA DA CONSTRUÇÃO CIVIL NO ESTADO DE SÃO PAULO SINDUSCON-SP. Setor da Construção em Números. 2003. Disponível em: www.sindusconsp.com.br. Acesso em 4 mar. 2008.

US BUREAU OF LABOR STATISTICS. Career guide to industries: Construction. Disponível em: www.bls.gov. Acesso em 3 mar. 2008.

\section{SITES PESQUISADOS}

Associação Brasileira dos Materiais de Construção http://www.abramat.org.br/. Associação Brasileira de Normas Técnicas (ABNT) www.abnt.org.br

\section{FEDERAÇÃO DAS INDÚSTRIAS DO ESTADO} DE SÃO PAULO-FIESP www.fiesp.org.br

Ministério da Educação e Cultura (MEC) www. mec.gov.br
Ministério das Cidades: http://www.cidades. gov.br/secretarias-nacionais/secretaria-dehabitacao/planhab/biblioteca/projecao-dademanda-demogafica-habitacional/projecaoda-demanda

PORTAL EXAME www.portalexame.abril. com.br

SINDUSCON DF www.sinduscondf.org.br
US CENSUS BUREAU www.census.gov

http://nwjoinery.com

www.publicworks.houstontx.gov

http://www.businessstrategies.co.uk

http://epp.eurostat.ec.europa.eu

http://www.oracle.com

\section{SOBRE OS AUTORES}

\section{Luiz Carlos Brasil de Brito Mello}

Departamento de Engenharia de Produção

Universidade Federal Fluminense - UFF

End.: Rua Passo da Pátria,156, sala 241, Bloco D - Niterói - RJ

Tel.: (21) 2629-5617Ｅ-mail: luiz.brasil@gmail.com

\section{Sérgio Roberto Leusin de Amorim}

Universidade Federal Fluminense - UFF

End.: Rua Passo da Pátria, 156, sala 365, bloco D - Niterói - RJ

Tel.: (21) 2629-5490 E-mail: sergio.leusin@gmail.com 